\title{
EFEKTIVITAS KONSELING BEHAVIORAL DENGAN TEKNIK MODELING MELALUI LESSON STUDY UNTUK MENINGKATKAN SELF NURTURANCE
}

\author{
I Ketut Dharsana ${ }^{1}$, Ni Ketut Suarni' ${ }^{2}$, I Gusti Ngurah Adi Mahendra ${ }^{3}$ \\ 1,2,3 Jurusan Bimbingan Konseling \\ Universitas Pendidikan Ganesha \\ Singaraja, Indonesia \\ e-mail: Profdarsana@yahoo.com¹, tutarni@yahoo.com², \\ mahendraadi54@gmail.com ${ }^{3}$
}

\begin{abstract}
Abstrak
Tujuan penelitian ini adalah untuk mengetahui Efetivitas Konseling Behavioral Dengan Teknik modeling melalui lesson study untuk meningkatkan Self Nurturance siswa kelas X BDPM A SMK Negeri 1 Singaraja. Penelitian ini termasuk "quasi exsperiment". Desain eksperimen yang digunakan adalah Pretest Postest Control Group Design. Populasi penelitian ini adalah siswa siswi kelas X SMK Negeri 1 Singaraja yang berjumlah 71 siswa. Melalui teknik random sampling, 34 siswa ditempatkan dikelompok eksperimen dan 37 siswa ditempatkan pada kelompok kontrol. Metode pengumpulan data dalam penelitian ini menggunakan metode observasi, wawancara, buku harian dan kuesioner Self Nurturance. Kuesioner self nurturance telah teruji validitas dan realibilitasnya. Analisis data kuesioner menggunakan metode Alpha Cronbach. Penelitian in menggunakan uji Independent Samples t-test dengan bantuan JASP Version 0.7.5.5 menunjukkan nilai hasil uji hipotesis menggunakan Independent Samples t-test, mendapatkan $t=9.347$ dengan $p<0.05$. Pengujian Effect Size (ES) menunjukkan tingkat keefektifan yang tinggi $(E S=2.221)$. Hasil tersebut membuktikan bahwa konseling behavioral dengan teknik modeling efektif untuk meningkatkan Self Nurturance siswa kelas X di SMK Negeri 1 Singaraja.
\end{abstract}

Kata-kata kunci : Konseling Behavioral, Lesson Study, Self Nurturance, Teknik Modeling

\begin{abstract}
This study aims to determine the difference of Fifth grade IPS learning outcomes of elementary school in Gugus II Tejakula Sub-district on even semester of 2017/2018 between group of students who are taught using Course Review Horay learning model with audio visual and group of students who are not taught using Course Review Horay learning model. This research is quasi experiment with non equivalent design post-test only control group design. The population of this study is all Fifth grade of elementary school students in Gugus II Tejakula sub-district academic year 2016/2017 in total of 162 students. The sample in this study is Fifth grade students of SD Negeri 5 Les in total 30 students and Fifth grade students of SD Negeri 1 Les counted 39 people, determined by random sampling technique. The result was obtained through multiple choice instrument test method which analyzed by using descriptive statistical and inferential statistical test (t-test). The result showed that there was a significant effect of IPS learning outcomes between groups of students who were taught using learning model of Course Reviews Horay helped by audio visual media and group of students who were not taught of using Course Review Horay model, with t-count $=2,384$ bigger than $\mathrm{t}$-tab $=$ 1,980. This means that the difference application of learning model can affect the Fifth grade's IPS learning outcomes in Gugus II Tejakula sub-district even semester of academic year 2017/2018. Recommendation for the teachers in improving the Fifth grade's IPS learning outcomes in Sub-district II Tejakula is to use learning model of Course Review Horay assisted by audio visual media.
\end{abstract}

Keywords: Behavioral Counseling, Lesson Study, Self Nurturance, Modeling Techniqu 


\section{Pendahuluan}

Pendidikan mempunyai peranan yang sangat penting dalam pengembangan manusia seutuhnya. Oleh karenanya pendidikan sangat perlu untuk dikembangkan dari berbagai aspek utamanya pendidikan karakter, pendidikan karakter dapat dilakukan dengan mengembangkan kemampuan-kemampuan yang ada pada diri pribadi individu, antara lain: konsep diri, komunikasi diri, emosi diri, harga diri, daya tahan, atau keyakinan akan kemampuan diri (efikasi diri).

Belakangan ini terdapat permasalahan yang terjadi khususnya di kalangan pelajar siswa di sekolah. Banyak siswa yang masih belum paham betul tentang bagaimana dirinya sehingga yang mereka lakukan di sekolah kebanyakan hanya mengikuti apa yang dilakukan oleh temannya saja. Di lingkungan sekolah banyak hal yang menunjukan siswa kurang mampu dengan baik misalnnya saja siswa kurang mampu menyenangkan hati orang lain, siswa kurang mampu membantu orang lain maupun teman sendiri, dan siswa kurang memiliki sifat simpati dan empati terhadap orang lain di lingkungan sekolah maupun di lingkungan masyarakat. Jadi disinilah pentingnya siswa memahami kepribadian yang mereka miliki agar mereka lebih peka dengan lingkungan sekolah maupun lingkungan masyarakat dan dapat membantu orang lain serta bersifat simpati dan empati. Kepribadian yang perlu siswa ketahui yang ada pada dirinya adalah tentang Self Nurturance

Pengamatan peneliti terhadap siswa dikelas ditemukan bahwa: sebagian siswa mampu menunjukan sikap menyenangkan hati orang lain sebagian lagi menunjukan sikap tidak bisa menyenangkan hati orang lain. Sebagian siswa mampu menunjukan perilaku membantu orang lain sebagian lagi menunjukan perilaku tidak suka membantu orang lain. Sebagian siswa mampu menunjukan sifat simpati dan empati kepada orang lain sebagian lagi menunjukan tidak memiliki sifat simpati dan empati.

Hasil wawancara peneliti terhadap siswa di kelas menunjukkan bahwa: hampir semua siswa melaporkan bahwa mereka mampu menyenangkan hati orang lain sebaliknya sebagian lagi menunjukan tidak bisa untuk menyenangkan hati orang lain. Sebagian siswa mampu menunjukan sikap membantu orang lain sebaliknya sebagian lagi tidak suka untuk membantu orang lain. Sebagian siswa mampu menunjukan sifat simpati dan empati kepada orang lain sebaliknya sebagian lagi menunjukan tidak memiliki sifat simpati dan empati kepada orang lain.

Berdasarkan hasil observasi dan wawancara yang dilakukan peneliti saat melaksanakan PLBKS dan Penelitian di SMK Negeri 1 Singaraja. Peneliti melihat beberapa siswa di kelas $X$ menunjukkan gejala-gejala self nurturance rendah. Dalam hal ini, siswa yang dijadikan sampel oleh peneliti adalah siswa kelas X BDPM A sebagai kelas Eksperimen dan X BDPM B sebagai kelas Kontrol SMK Negeri 1 Singaraja. Selain dengan melakukan observasi terhdap siswa juga dilakukan wawancara untuk mendapatkan data yang lebih akurat tentang gejala self nurturance. Hasil wawancara yang dilakukan peneliti terhadap kelas X BDPM A SMK Negeri 1 Singaraja. Berdasarkan hasil pengamatan peneliti pada tabel hasil wawancara dapat disimpulkan bahwa $61.76 \%$ tergolong memiliki self nurturance rendah. Seperti dalam populasi tersebut perilaku siswa tergolong dalam 3 katagori yaitu siswa yang tergolong memiliki Self nurturance tinggi, siswa yang tergolong memiliki Self nurturance sedang dan siswa yang tergolong memiliki Self nurturance rendah. Siswa yang tergolong memiliki Self nurturance tinggi yang menunjukan perilaku seperti suka menghibur perasaan teman yang sedang sedih, suka menolong teman yang sedang kesusahan, dan memiliki sifat simpati dan empati kepada orang lain. Selain itu ada siswa yang tergolong memiliki Self nurturance sedang, gejala prilaku seperti: terkadang suka untuk menyenangkan hati orang lain, terkadang bisa untuk menolong atau membantu teman, dan terkadang memiliki sifat simpati dan empati kepada orang lain. Sedangkan siswa yang tergolong memiliki Self nurturance rendah menunjukkan perilaku seperti: tidak suka mampu menyenangkan hati orang lain, tidak mampu menolong orang lain, dan kurang memiliki sifat simpati dan empati.

Adapun Faktor yang menyebabkan rendahnya self nurturance pada siswa kelas $X$ BDPM A SMK Negeri 1 Singaraja karena kemampuan seseorang untuk menyenangkan hati orang lain dapat dikategorikan ke dalam dua kelompok, yaitu yang dapat dikategorikan sebagai 
individu-individu yang mampu menyenangkan hati orang lain dan sebaliknya yaitu individuindividu yang tidak mampu menyenangkan hati orang lain. Individu yang mampu menyenangkan hati orang lain. Mereka akan mudah untuk bergaul dan mendapatkan teman baru karena sikap dan sifatnya yang mampu menyenangkan hati orang lain. Kemampuan seseorang untuk membantu orang lain dapat dikategorikan ke dalam dua kelompok, yaitu yang dapat dikategorikan sebagai individu-individu yang mampu menolong orang lain dan sebaliknya yaitu individu-individu yang tidak mampu menolong orang lain. Individu yang mampu menyenangkan hati orang lain. Mereka akan lebih banyak mendapatkan keberuntungan dan kemudahan jika mereka memerlukan bantuan. Kemampuan seseorang untuk bersifat simpati dan empati dapat dikategorikan ke dalam dua kelompok, yaitu yang dapat dikategorikan sebagai individu-individu yang memiliki sifat simpati dan empati dan sebaliknya yaitu individuindividu yang tidak memiliki sifat simpati dan empati. Individu yang memiliki sifat simpati dan empati. Mereka lebih memiliki kepekaan sosial yang sangat tinggi, dan jika mereka terkena musibah orang lain pasti akan bersifat simpati dan empati kepada mereka, merasakan apa yang orang lain rasakan.

Apabila Self nurturance yang rendah tersebut tidak segera diatasi maka hal ini akan berakibat pada kurangnya interaksi sosial yang baik antar siswa di sekolah maupun dengan guru di sekolah, kurangnya kepekaan sosial siswa untuk memiliki sifat simpati dan empati kepada orang lain. Terkait dengan permasalahan tersebut, kenyataan di lapangan menggambarkan bahwa dengan adanya Bimbingan Konseling di sekolah dapat menangani berbagai permasalahan yang memang merupakan kajian dari tugas BK. Kondisi yang terjadi di lapangan tersebut, mengindikasi bahwa Self nurturance siswa masih ada pada kategori kurang dan perlu untuk di tingkatkan.

Selain itu adapun upaya pelatihan melalui kegiatan ekstrakurikuler. Ekstrakurikuler merupakan kegiatan tambahan yang diikuti peserta didik yang berada dalam naungan sekolah. Sedangkan Bimbingan Konseling Menurut (Dharsana, 2015) Suatu proses pemberian bantuan yang dilakukan konselor kepada konseli agar konseli mampu menyelesaikan masalah yang dihadapinya dan juga mampu mengembangkan potensi yang dimilikinya seoptimal mungkin secara mandiri. Sehubungan dengan hal tersebut, maka peneliti memilih untuk mengembangkan Self nurturance siswa melalui pendekatan bimbingan konseling.

Upaya meningkatkan self nurturance tersebut peneliti menggunakan model Konseling behavioral adalah suatu pandangan ilmiah tentang tingkah laku manusia yang merupakan suatu proses belajar, sehingga dapat diubah dengan memanipulasi dan mengkresi kondisikondisi belajar dan dengan penerapan aneka ragam teknik dan prosedur dalam membantu klien memecahkan masalah interpersonal, emosional dan pengambilan keputusan sehingga terbentuk kebiasaan-kebiasaan baru yang berguna bagi hidup individu. Serta suatu proses konseling yang digunakan untuk meningkatkan Self nurturance dalam pembentukan responrespon tingkah laku dengan prosedur dan langkah, skill konseling melalui konseling kelompok.

Dalam penelitian ini peneliti memilih satu teknik yaitu teknik Modeling. Menurut Bandura (dalam Mochamad Nursalim, 2013:121) menyatakan bahwa yang dimaksud modeling adalah suatu teknik dalam konseling yang menggunakan proses belajar melalui pengamatan model dan perubahan perilaku yang terjadi karena peniruan. Menurut Yulianto (2017) Teknik modelling merupakan observasi permodelan, mengobservasi seseorang lainnya sehingga seseorang tersebut membentuk ide dan tingkah laku, kemudian dijelaskan sebagai panduan untuk bertindak. Teknik modeling ini dapat digunakan untuk membentuk tingkah laku baru pada konseli, dan dapat memperkuat tingkah laku yang sudah terbentuk". Dalam hal ini konselor menunjukkan pada konseli tentang tingkah laku model, dapat menggunakan model audio, model fisik, model hidup atau lainnya yang teramati dan dipahami jenis tingkah laku yang hendak dicontoh. Modeling merupakan salah satu teknik konseling yang dikembangkan oleh Albert Bandura yang berakar dari teori belajar (social learning). Menurut Bandura (dalam Mochamad Nursalim, 2013:121) menyatakan bahwa yang dimaksud modeling adalah suatu teknik dalam konseling yang menggunakan proses belajar melalui pengamatan model dan perubahan perilaku yang terjadi karena peniruan. 
Berdasarkan latar belakang di atas, maka dapat dilakukan penelitian yang berjudul "Efektivitas Konseling Behavioral dengan Teknik Modeling melalui lesson study untuk Meningkatkan Self nurturance Siswa Kelas X BDPM A SMK Negeri 1 Singaraja".

Sejalan dengan rumusan masalah tersebut maka tujuan dari penelitian ini adalah : Untuk mengetahui Efektifitas Konseling Behavioral dengan Teknik Modeling melalui lesson study Efektif untuk Meningkatkan Self nurturance Siswa Kelas X BDPM A SMK Negeri 1 Singaraja.

Manfaat yang diharapkan dalam penelitian ini antara lain : 1. Manfaat Teoritis yaitu Hasil penelitian ini diharapkan mampu memberikan kontribusi yang baik dalam bidang ilmu pendidikan. Serta dapat menambah ilmu dalam bidang pendidikan khususnya kualitas dari guru BK di sekolah dalam menangani siswa yang bermasalah dan tentunya mengkhusus pada siswa yang memiliki perilaku sosial yang baik dalam lingkungan sekolah. 2. Manfaat Praktis yang pertama bagi guru BK. Manfaat hasil penelitian bagi guru BK yaitu : diharapkan dapat dijadikan sebagai masukan dalam mengimplementasikan pelaksanaan konseling dalam rangka meningkatkan self nurturance siswa kelas X BDPM A SMK Negeri 1 Singaraja. Bagi Peneliti dan Manfaat hasil penelitian bagi peneliti yaitu : peneliti dapat memperoleh pengalaman langsung bagaimana memilih teori serta teknik yang tepat dalam menangani siswa. Kemudian menyesuaikan dengan keadaan di lapangan, menyesuaikan dengan kebutuhan siswa. Mendapat gambaran secara langsung bagaimana menjadi seorang guru BK yang sesungguhnya, seorang guru BK yang langsung berhadapan dengan siswa. Bagi peneliti lain, hasil penelitian ini diharapkan bisa menjadi referensi dan informasi bagi peneliti yang ingin mengkaji lebih dalam lagi mengenai self nurturance siswa.

Lesson study bukan metode pembelajaran atau strategi pembelajaran, tetapi dalam lesson study dapat dipilih dan diterapkan berbagai metode atau strategi pembelajaran yang sesuai dengan situasi, kondisi, atau masalah pembelajaran yang dihadapi dosen dan mahasiswa. Dalam lesson study, dosen harus mengubah proses pembelajaran klasikal yang berorientasi kepada pengajar (Teacher Center Learning) menjadi pembelajaran yang berpusat pada mahasiswa (Student Center Learning) (Wiharto, 2017).

Self nurturance adalah kebutuhan untuk bisa menyenangkan hati orang lain, meliputi membantu teman bila keadaan susah, membantu orang kurang beruntung, mengobati orang lain dengan sifat simpati dan empati Dharsana, (2010,2014). Menurut Sugiyanto Self nurturance adalah untuk menolong teman dan orang lain yang mengalami kesulitan; untuk mengampuni dan berlaku dermawan terhadap orang lain. Sugiyanto, (1984:81-83).

Konseling behavioral adalah salah satu dari teori-teori konseling yang ada pada saat ini. Konseling behavioral merupakan bentuk adaptasi dari aliran psikologi behavioristik yang menekankan perhatiannya pada perilaku yang nampak. Konseling behavioral dikenal juga dengan modifikasi perilaku yang dapat diartikan sebagai tindakan yang bertujuan untuk mengubah perilaku. Behavioral merupakan bentuk adaptasi dari aliran konseling behavioristik, yang menekankan perhatiannya pada perilaku yang tampak.

\section{Metode}

Penelitian ini adalah quasi eksperimen, desain penelitian yang digunakan adalah Pretest-Posttest Control Group design. Dantes (2012:37) menyatakan bahwa "Populasi adalah sejumlah kasus yang memenuhi seperangkat kriteria tertentu, yang ditentukan penelitian". Subyek yang diambil 346 orang siswa. Sampel yang diambil adalah intact grup, yaitu satu kelas eksperimen dan satu kelas control.

Analisis reabilitas kuesioner self nurturance dilakukan hanya untuk butir yang valid. Untuk menentukan reabilitas digunakan rumus Alpha Cronbach. Dari hasil pengujian reabilitas dengan menggunakan metode analisis Rasch. Dalam penelitian ini, 30 butir soal selanjutnya diuji reliabilitas. Pada pengujian reliabilitas ini mengunakan metode koefisien Alpha $(\alpha)$ atau $r$ alpha. Dari hasil pengujian reliabilitas output analisis menggunakan analisis Rasch. Jadi instumen tersebut layak dan dapat dipercaya untuk digunakan sebagai alat pengumpul data dalam penelitian ini. 
Kelompok Eksperimen diberikan treatmen dengan Konseling Behavioral dengan teknik modeling yang dilakukan selama 9 kali pertemuan. Setelah pemberian treatmen selesai, selanjutnya kepada seluruh kelompok eksperimen dan control diberikan kuesioner postest. Data yang diperoleh melalui postest dianalisis dengan uji t.

\section{Hasil dan Pembahasan}

Penelitian ini adalah penelitian yang dilakukan pada 2 kelompok yaitu, kelompok eksperimen dan kelompok control. Dalam penelitian ini kelompok eksperimen diberikan perlakuan berupa model konseling modeling dengan modeling, sedangkan kelompok control mengikuti pembelajaran dikelas. Data hasil self nurturance siswa diperoleh melalui tes masingmasing kelompok. Data yang dianalisis adalah Gain Score. Rangkuman analisis data hasil self nurturance siswa pada kelompok eksperimen dan kelompok control tercantum pada Tabel 1 berikut :

Tabel 1. Analisis Deskriptif Self Nurturance dengan Teknik Modeling

\begin{tabular}{lcccccc}
\hline \multicolumn{1}{c}{ Statistik } & \multicolumn{3}{c}{ Kelompok eksperimen } & \multicolumn{2}{c}{ kelompok kontrol } & \\
& pretest & postest & Gain score & pretest & postest & Gain Score \\
\hline mean & 118.59 & 140.26 & 21.68 & 119.70 & 123.70 & 4.00 \\
median & 116.50 & 140.00 & 23.50 & 121.00 & 125.00 & 4.00 \\
modus & 122.00 & 140.00 & 18.00 & 121.00 & 126.00 & 5.00 \\
standar deviasi & 12.43 & 5.66 & -6.77 & 14.79 & 8.79 & -6.00 \\
Varians & 154.55 & 32.02 & -122.53 & 218.88 & 77.27 & -141.61 \\
Nilai minimun & 87.00 & 127.00 & 40.00 & 91.00 & 100.00 & 9.00 \\
nilai maksimum & 147.00 & 150.00 & 3.00 & 148.00 & 139.00 & -9.00 \\
\hline
\end{tabular}

Berdasarkan analisis yang telah dilakukan dengan menggunakan JASP 0.7.5.5 for Windows 7. Berdasarkan hasil uji normalitas sebaran data posttest kelompok eksperimen tersaji pada tabel berikut:

Tabel 2. Test of Normality (Shapiro-Wilk)

\begin{tabular}{llll}
\hline & & $\mathbf{W}$ & $\mathbf{P}$ \\
\hline $\mathrm{Y} 1$ & 1 & 0.977 & 0.660 \\
& 2 & 0.951 & 0.106 \\
$\mathrm{Y} 2$ & 1 & 0.973 & 0.558 \\
& 2 & 0.959 & 0.189 \\
\hline
\end{tabular}

Pengujian dilakukan pada taraf signifikansi 0.05 Berdasarkan hasil uji normalitas sebaran data diketahui nilai $p=0.106$ pada kelas eksperimen sehingga $p>0.05$, maka dapat diartikan bahwa sebaran data kelas eksperimen berdistribusi normal. Sedangkan pada kelas kontrol didapatkan $p=0.189$ pada kelas kontrol sehingga $p>0.05$, maka dapat diartikan bahwa sebaran data kelas kontrol berdistribusi normal. 
Tabel 3. Test of Equality of Variances (Levene's)

\begin{tabular}{llll}
\hline & $\mathbf{F}$ & $\mathbf{d f}$ & $\mathbf{p}$ \\
\hline $\mathrm{Y} 1$ & 0.889 & 1 & 0.349 \\
$\mathrm{Y} 2$ & 3.729 & 1 & 0.058 \\
\hline
\end{tabular}

Pengujian dilakukan pada taraf signifikansi 0.05 Berdasarkan hasil uji normalitas sebaran data diketahui nilai $0.349>0.05$ untuk pretest, maka dapat diartikan bahwa data tersebut bersifat homogen. data diketahui nilai $0.058>0.05$ untuk postest, maka dapat diartikan bahwa data tersebut bersifat homogen.

Tabel 4. Independent Samples T-Test

\begin{tabular}{lllll}
\hline & $\mathbf{T}$ & $\mathbf{d f}$ & $\mathbf{p}$ & Cohen's d \\
\hline $\mathrm{Y} 1$ & -0.342 & 69.00 & 0.733 & -0.081 \\
$\mathrm{Y} 2$ & 9.347 & 69.00 & $<.001$ & 2.221 \\
\hline
\end{tabular}

Berdasarkan Tabel 4 hasil analisis data didapat $\mathrm{t}=(69)=9.347>0.05$ p. Maka didapatkan nilai $0.001<0.005$. ini berarti Ha diterima. "Terdapat perbedaan self nurturance antara siswa yang diberikan konseling behavioral dengan teknik modeling dan siswa yang diberikan konseling konvensional pada siswa kelas X di SMK Negeri 1 Singaraja" diterima.

\section{Simpulan dan Saran}

Pembahasan hasil penelitian akan dipaparkan berdasarkan hasil analisis data yang telah disajikan. Penelitian ini bertujuan untuk membuktikan bahwa Efektivitas konseling behavioral dengan teknik modeling efektif terhadap siswa kelas X BDPM A SMK Negeri 1 Singaraja, dan terdapat perbedaan antara siswa yang diberikan konseling behavioral teknik modeling dengan siswa yang tidak diberikan konseling behavioral teknik modeling. Kegiatan inti dalam konseling behavioral teknik modeling yaitu memperbaiki sikap serta pemberian simbolik model berupa film/video yang berkaitan dengan Self-Nurturance kepada kelompok eksperimen agar siswa dapat merefleksikan di kehidupan sehari-hari. Pemberian konseling behavioral pada treatment yang paling menonjol memberikan perubahan yang signifikan, hal ini dapat dilihat dari hasil analisis. Berikut pembahasan masing-masing tujuan berdasarkan analisis data sebelumnya.

Hasil penelitian menunjukkan bahwa konseling behavioral dengan teknik modeling untuk meningkatkan self nurturance siswa. Hasil penelitian ini sesuai dengan teori yang menyatakan bahwa konseling behavioral teknik modeling mampu mengubah pola pikir siswa atau subjek treatment yang akan diikuti dengan perubahan tingkah lakuknya.

Hasil Analisis dapat didapatkan $t=9.347>0.05$ p. Maka didapatkan nilai $0.001<0.005$. ini berarti $\mathrm{Ha}$ diterima. "Terdapat perbedaan self nurturance antara siswa yang diberikan konseling behavioral dengan teknik modeling dan siswa yang diberikan konseling konvensional pada siswa kelas X di SMK Negeri 1 Singaraja" diterima.

\section{Daftar Pustaka}

Corey, Gerald. 2013. Teori dan Prakterk Konseling dan Psikoterapi.Jakarta: Refika Aditama

Dantes. 2012. Metode Penelitian. Jakarta:Salemba Empat

Dharsana, K. (2013). Modul Teori-Teori Konseling. Singaraja: Jurusan Bimbingan Konseling, FIP UNDIKSHA.

Dharsana, Ketut. 2013. Teori-teori konseling. Singaraja: Universitas Pendidikan Ganesha. 
Dharsana, Ketut. 2014. Model-model, Teori, Teknik, Skill Bimbingan Konseling. Singaraja: Universitas Pendidikan Ganesha.

Dharsana, K. (2014a). Model-model konseling, teori-teori konseling. (J. B. Konseling, Ed.). singaraja.

Dharsana, K. (2014b). Model-Model Teori, Teknik, Skill Bimbingan Konseling. (J.B.K.F.I.P.U.P. Ganesha, Ed.). Singaraja.

Dharsana K. (2010). Model-Model Konseling. Singaraja: Profit Press.

Sugiyanto,1984. Psikologi Pendidikan:Semarang.Unnesa

Sukardi. 2003. Metodologi Penelitian Pendidikan.Jakarta: Bumi Aksara

Wiharto, M. 2017. Kegiatan Lesson Study Dalam Pembelajaran. In FGD-Pengayaan Pengembangan Kurikulum Pendidikan Tinggi. Kementrian Riset Teknologi dan Pendidikan Tinggi (pp. 22-30).

Yulianto, Ardhitya Dwi. 2017. Pengaruh Bimbingan Kelompok dengan Teknik Modeling untuk Mengurangi Perilaku Agresif pada Siswa Kelas VIII SMP Negeri 3 Weru Tahun Pelajaran 2017/2018. Jurnal IImiah Konseling Vol.17 No. 1 Hal. 1-10. Tersedia Pada: http://ejournal.utp.ac.id/index.php/JIK/article/download/591/633. 